\title{
RESPONSABILIDADE INTERNACIONAL DO ESTADO E OS DIREITOS HUMANOS: O CASO DA LEI MARIA DA PENHA NO BRASIL
}

\section{ARTIGO ORIGINAL}

MACÊDO, Karen Vanderlei ${ }^{1}$

MACÊDO, Karen Vanderlei. Responsabilidade Internacional do Estado e os Direitos Humanos: $O$ caso da Lei Maria da Penha no Brasil. Revista Científica Multidisciplinar Núcleo do Conhecimento. Ano 05, Ed. 11, Vol. 22, pp. 57-70. Novembro de 2020. ISSN: 2448-0959, Link de acesso:https://www.nucleodoconhecimento.com.br/lei/responsabilidade-internacional

\section{RESUMO}

O objetivo central deste artigo é analisar a Responsabilidade Internacional do Estado brasileiro no caso de violência à mulher, em particular, ao caso que se tornou emblemático no Brasil e fora dele, que foi o acometimento de violência contra Maria da Penha Maia Fernandes praticada por, hoje, o seu ex-marido. Aqui a referência é o caso 12.051 (Maria da Penha Maia Fernandes versus Brasil), que foi aberto no dia 20 de agosto de 1998 pela Comissão Interamericana de Direitos Humanos da Organização dos Estados Americanos (OEA). A partir da interseção entre a violência doméstica cometida contra Maria da Penha Maia Fernandes e o instituto da Responsabilidade Internacional, verificou-se como a aplicação de um instituto internacional, por meio da Comissão Interamericana de Direitos Humanos da Organização dos Estados Americanos (CIDH-OEA) influenciou a criação de uma legislação que assegura os direitos das mulheres no Estado brasileiro.

${ }^{1}$ Graduação em Direito (Estácio CEUT), Especialização em Gestão Pública com ênfase em licitação de contratos (FAR); Especialização em Direito Público (FAR, em andamento) e Mestrado em Direito Público (Universidade Portucalense, em andamento). 
Palavras-Chave: Responsabilidade Internacional, OEA, Maria da Penha.

\section{INTRODUÇÃO}

O tratamento do tema das responsabilidades ou reparações na área de violações de direitos humanos é relativamente recente. Tal temática toma corpo após a barbárie da Segunda Guerra Mundial e outros conflitos internacionais ou internos que ocorreram ao longo do século $\mathrm{XX}$, no qual ocasionaram consequências terríveis. Para a integridade dos seres humanos, foram promovidos o nascimento e a evolução de sistemas de promoção e proteção dos direitos humanos, citando como exemplos relevantes os casos da Corte Europeia de Direitos Humanos e da Corte Interamericana de Direitos Humanos (ALEXANDRINO, 2017; BOTELHO; TABISZ, 2017; BOTELHO, 2005; RAMOS, 2005).

A proteção dos direitos humanos baseia-se na ideia de responsabilidade dos Estados, entendida como a obrigação de garantir que esses direitos não sejam afetados ou prejudicados, sendo este objeto de especial preocupação quando os Estados poderem ser autores de violações à lei, direitos dos seus cidadãos e das pessoas dentro das suas fronteiras (Botelho, 2005; Ramos, 2005). Para entender a defesa dos direitos fundamentais da pessoa, é necessário esclarecer onde surge a obrigação do Estado, isto é, a responsabilidade internacional do Estado.

Da mesma maneira faz-se relevante analisar a prática da responsabilidade internacional do Estado, isto é, a partir de um caso concreto. Esse é o objetivo deste artigo, analisar a responsabilidade internacional do Brasil perante um caso de violação de Direitos Humanos. Aqui o caso é o de violação aos direitos das mulheres, em particular, cometido contra Maria da Penha Maia Fernandes. Esse caso ficou bastante conhecido tanto nacional, quanto internacionalmente, isso não por ser um apelo individual, mas que tal apelo particular se fazia e ainda se faz a uma prática frequente no Brasil, qual seja: a violência contra a mulher, isto é, uma constante violação dos direitos humanos da população feminina brasileira. 
Dessa forma, o objetivo central deste artigo é analisar a Responsabilidade Internacional do Estado brasileiro no caso de violência à mulher, em particular, ao caso que se tornou emblemático no Brasil e fora dele, que foi o acometimento de violência contra Maria da Penha Maia Fernandes praticada por, hoje, o seu ex-marido. Aqui a referência é o caso 12.051 (Maria da Penha Maia Fernandes versus Brasil), que foi aberto no dia 20 de agosto de 1998 pela Comissão Interamericana de Direitos Humanos da Organização dos Estados Americanos (OEA).

Para a consecução deste artigo utilizou-se uma análise qualitativa, em particular, ao utilizar a técnica da revisão bibliográfica sobre a temática da responsabilidade internacional, assim como acerca do caso de Maria da Penha Maia Fernandes. Foram, ainda, utilizados documentos, como Draft articles on Responsibility of States for Internationally Wrongful Acts (ONU, 2001) produzido pela Comissão de Direito Internacional das Nações Unidas, essencial para a aplicação da responsabilidade internacional do Estado, assim como o Informe 54/01, caso 12.051, Maria da Penha Fernandes versus Brasil, de 16/04/2001 (OEA, 2001).

Este artigo está dividido em três partes, quais sejam: a) aspectos sobre a responsabilidade internacional do Estado; b) breve relato sobre a trajetória do caso Maria da Penha Maia Fernandes, e; c) correlação entre responsabilidade internacional do Estado e o caso Maria da Penha Maia Fernandes.

\section{ASPECTOS SOBRE A RESPONSABILIDADE INTERNACIONAL DO ESTADO}

Como instituição do direito internacional, a responsabilidade internacional tem uma origem no direito consuetudinário e está relacionada à figura do Estado como o único assunto do direito internacional público, no qual se baseou inicialmente no dano causado aos nacionais de um Estado em outro. Posteriormente, foi aplicada a conflitos armados entre Estados e atualmente se estende a todos os atos ilícitos de um Estado, sem prejuízo do fato de que a figura da responsabilidade internacional se aplica atualmente a outros assuntos de direito internacional, como organizações 
internacionais e indivíduos (ALEXANDRINO, 2017; BOTELHO; TABISZ, 2017; BOTELHO, 2005; RAMOS, 2005).

Para explicar a responsabilidade do Estado sob o direito internacional, é necessário primeiro se referir aos tipos de responsabilidade que o Estado pode incorrer. Além disso, é importante diferenciar as áreas em que é imperativo que os esforços de codificação sejam retomados. O direito internacional contemporâneo permite distinguir entre a responsabilidade internacional gerada por atos ilegais atribuíveis aos Estados e a responsabilidade que, sem a existência de um ato ilegal, decorre do desempenho de atividades que não são proibidas quando causam danos a terceiros. Portanto, com base no direito internacional, os Estados podem incorrer em responsabilidade internacional também quando seus atos legais causarem danos transfronteiriços a outros Estados ou a seus habitantes (ALEXANDRINO, 2017; BOTELHO; TABISZ, 2017; BOTELHO, 2005; RAMOS, 2005).

De acordo com Ramos (2005, p. 53),

[...] vê-se que a responsabilidade internacional do Estado consiste, para parte da doutrina, em uma obrigação internacional de reparação em face de violação prévia de norma internacional. A responsabilidade é característica essencial de um sistema jurídico, como pretende ser o sistema internacional de regras de conduta, tendo seu fundamento de Direito Internacional no princípio da igualdade soberana entre os Estados. Com efeito, todos os Estados reivindicam o cumprimento dos acordos e tratados que os beneficiam e, por consequência, não podem recusar-se a cumprir os acordos e tratados, uma vez que todos eles são iguais. Sendo assim, um Estado não pode reivindicar para si uma condição jurídica que não reconhece a outro.

A partir do exposto, pode-se perceber que um ato cometido por um Estado que seja interpretado como um ato ilícito internacional pode ser passível de análise por parte dos Tribunais Internacionais. Entende-se por ato ilegal internacional o ato atribuível a um sujeito jurídico internacional que, constituindo uma violação ou infração à lei internacional, danifique os direitos de outros sujeitos do referido sistema ou mesmo direitos ou interesses aos quais a própria comunidade internacional teria direito, dando origem, entre outras possíveis consequências, à responsabilidade do autor do ato (BOTELHO, 2005). 
O ato ilícito internacional é composto de dois elementos, a saber: um elemento subjetivo e um elemento objetivo. Quando falamos do elemento subjetivo, nos referimos ao comportamento pelo qual os regulamentos internacionais não são cumpridos e podem ser atribuídos ao Estado, considerando que esse sujeito do direito internacional é uma pessoa moral que age por seus órgãos, individuais ou coletivos, que gera um evento atribuível ao Estado.

O elemento objetivo do ato ilegal internacional é constituído por um comportamento que constitui uma violação de uma obrigação internacional do Estado. De acordo com Alexandrino (2017) e Botelho (2005), a violação de uma obrigação internacional consiste na falta de conformidade entre o comportamento que essa obrigação exige do Estado e o comportamento que o Estado observa de fato, ou seja, entre os requisitos do direito internacional e a realidade dos fatos. É necessário destacar que considerar o ato ilícito como decorrente de uma violação de uma obrigação do direito internacional terá como consequência a inclusão de premissas como obrigações assumidas por atos unilaterais dos Estados ou por atos de organizações internacionais.

O comportamento que gera o ato ilícito pode ser constituído por uma ação, ou omissão, ou uma combinação de ambos. Pode se manifestar, por exemplo, com a promulgação de uma regra interna específica em um caso específico. De acordo com Alexandrino (2017), Botelho e Tabisz (2017), Botelho (2005) e Ramos (2005), ao descrever a violação de uma obrigação internacional, a Comissão de Direito Internacional das Nações Unidas faz uma distinção entre crimes internacionais e crimes nacionais. O primeiro conceito implicaria a violação de uma obrigação internacional tão essencial para salvaguardar os interesses fundamentais da comunidade internacional que sua violação é reconhecida como crime por essa comunidade como um todo.

Essa primeira categoria inclui, entre outras, graves violações das obrigações internacionais de importância essencial com relação à manutenção da paz e segurança internacional, o direito à autodeterminação dos povos, a salvaguarda e a proteção do meio ambiente humano e as graves violações. E em larga escala, uma 
obrigação internacional de importância essencial para a salvaguarda do ser humano, como as que proíbem a escravidão, o genocídio e o apartheid. Um crime internacional e qualquer ato internacionalmente ilegal que não seja um crime internacional (ALEXANDRINO, 2017; BOTELHO; TABISZ, 2017; BOTELHO, 2005; RAMOS, 2005).

Em relação ao direito internacional dos direitos humanos, a responsabilidade do Estado surge quando um Estado viola a obrigação de respeitar os direitos humanos reconhecidos internacionalmente. Essa obrigação tem sua base legal em acordos internacionais, em particular, tratados internacionais de direitos humanos e, particularmente, nas normas do direito internacional consuetudinário que são obrigatórias (jus cogens). Assim, os Estados têm não apenas o dever de respeitar os direitos humanos reconhecidos internacionalmente, mas também o dever de garantir esses direitos, o que pode implicar a obrigação de garantir o cumprimento de obrigações internacionais por pessoas privadas e a obrigação de evitar violações. Em caso de os Estados não aplicarem a devida diligência na tomada de medidas apropriadas ou na prevenção de violações estruturadas dos direitos humanos, os governos assumem a responsabilidade tanto legal como moralmente. Em relação aos direitos humanos, podemos dizer que são obrigações erga omnes para os Estados, isto é, são um conjunto de normas universais e imperativas que, como afirmado na Carta das Nações Unidas, afirmada pela Declaração Universal dos Direitos Humanos e aceita por quase todos os Estados, são obrigatórias para todos os membros da comunidade internacional. (ALEXANDRINO, 2017; BOTELHO; TABISZ, 2017; BOTELHO, 2005; RAMOS, 2005).

No caso de atos ilegais excepcionalmente graves, atribuíveis aos Estados, a responsabilidade internacional do Estado também é agravada e pode se manifestar com sanções exemplares ou dissuasivas. Além disso, a responsabilidade nesses casos pode implicar a obrigação de fazer alterações legislativas internas ou mesmo modificar sua regra fundamental, incluindo obrigações de Estados terceiros, como o não reconhecimento de conduta ilegal e a obrigação de não cooperar. Mas deve-se esclarecer que, em relação à sua participação na prática de crimes internacionais, o Estado não é adequadamente criminalizado, ou seja, não lhe é atribuída 
responsabilidade criminal, mas responsabilidade internacional e, consequentemente, a obrigação de reparar e conceder garantias de não repetição (ALEXANDRINO, 2017; BOTELHO; TABISZ, 2017; BOTELHO, 2005; RAMOS, 2005; ONU, 2001). Sendo assim, de acordo com Ramos (2005, p. 60), "a comunidade internacional pode lançar mão de sanções para coagir o Estado a respeitar os direitos humanos, alçados agora ao status de obrigação internacional”.

\section{BREVE RELATO SOBRE A TRAJETÓRIA DO CASO MARIA DA PENHA MAIA FERNANDES}

No Brasil, em 1983, a cidadã brasileira Maria da Penha Maia Fernandes foi vítima de uma dupla tentativa de homicídio perpetrada pelo seu marido, Marco Antônio Herredia Viveiros, que na época era economista e professor universitário. A primeira tentativa ocorreu no dia 29 de maio, quando ele desferiu-lhe um tiro pelas costas enquanto dormia, deixando-a lesionada e paraplégica. Enquanto no dia 06 de junho, na sua segunda oportunidade, ele tentou eletrocutá-la enquanto tomava banho (BASTERD, 2011).

Maria da Penha Maia Fernandes era apenas uma dentre diversas mulheres que sofriam violência doméstica no Brasil. De acordo com Santos e Izumino (2005), a violência contra a mulher não era codificada de maneira clara. Conforme as autoras, o Brasil iniciou a coleta de dados sobre violência contra a mulher nos anos de 1980, e os dados demonstraram que havia uma diferença na ocorrência de violência entre mulheres e homens. Ao longo dos anos de 1980, instituições públicas e privadas se envolveram em importantes pesquisas que ajudaram a mapear a situação no país. Foi também nesse período que a literatura sobre a violência contra a mulher começou a se desenvolver, com o objetivo de dar visibilidade a esse tópico.

O Instituto Brasileiro de Geografia e Estatística (IBGE) realizou a primeira pesquisa nacional sobre essa violência em 1988 e redigiu o Suplemento de Justiça e Vitimização. Segundo o Suplemento, as mulheres representavam quarenta e quatro por cento do número total de vítimas de agressão física no país. Esta foi a primeira 
estatística nacional desagregada por sexo em casos de ferimentos físicos e crimes patrimoniais relatados à polícia (SANTOS; IZUMINO, 2005).

Esses dados demonstram que a violência afeta homens e mulheres de uma maneira diferente. Enquanto para as mulheres, suas casas podem ser lugares perigosos e seus companheiros possíveis agressores, os homens são atacados principalmente por estranhos nas ruas. Com exceção do assédio sexual, as investigações sobre a violência contra as mulheres identificam predominantemente seus maridos ou parceiros como agressores. A violência é um dos principais problemas da sociedade brasileira. As mulheres brasileiras enfrentam situações violentas em dois cenários diferentes: como mulheres expostas à violência de gênero e como cidadãs expostas a formas distintas de violência que afetam a sociedade brasileira. Assim, esses dados revelam que a violência contra a mulher, especialmente a violência por parte do seu companheiro marital, é um fenômeno complexo e grave que exige o estabelecimento de um método sistemático para coletar e produzir dados, bem como a adoção de legislação específica e a ação estatal para combater o problema (SANTOS; IZUMINO, 2005).

De acordo com Santos e Izumino (2005, p. 158), na violência contra a mulher existe uma relação de poder entre homens e mulheres, em suas palavras:

Defendemos uma abordagem da violência contra as mulheres como uma relação de poder, entendendo-se o poder não de forma absoluta e estática, exercido via de regra pelo homem sobre a mulher, como quernos fazer crer a abordagem da dominação patriarcal, senão de forma dinâmica e relacional, exercido tanto por homens como por mulheres, ainda que de forma desigual.

Tal relação de poder foi verificada no caso de violência contra Maria da Penha Maia Fernandes. Mesmo quando buscou o Estado para a criminalização do ato de violência que sofreu do seu ex-companheiro, a justiça estatal em vez de reparar o dano de forma legal, optou por não cumprir o seu papel, uma vez que o agressor de Maria da Penha, mesmo após a condenação, passou 15 anos em liberdade, isto é, sem condenação na prática. Isso ocorre, conforme Santos e Izumino (2005, p. 155) para "[...] preservar a imagem tradicional da instituição familiar e do casamento". Isso 
demonstra, de acordo com as autoras, que antes da Lei Maria da Penha, as pesquisas demonstravam que, na prática, o Poder Judiciário tinha como objetivo buscar uma reconciliação do casal e não de criminalizar o agressor.

Como exposto, apesar de condenado pela Justiça local e passados quinze anos o agressor de Maria da Penha ainda permanecia em liberdade, valendo-se de sucessivos recursos processuais contra decisão condenatória do Tribunal do Júri. Frente a esse fato, cabe ressaltar que o Brasil, no ano de 1994, comprometeu-se a proteger e garantir os direitos das mulheres, em particular, no que diz respeito à violência sofrida constantemente pelas mulheres, isso ao assinar um Acordo Internacional na Convenção Interamericana para Prevenir, Punir e Erradicar a Violência contra a Mulher, a "Convenção de Belém do Pará".

Foi a partir dessas constatações que o caso de Maria da Penha Maia Fernandes tornou-se não apenas um caso de uma única mulher, mas das mulheres brasileiras que estão expostas constantemente à violência doméstica. $\mathrm{E}$ a partir do caso brutal de violência contra Maria da Penha, em 1998, a Comissão Interamericana de Direitos Humanos da Organização dos Estados Americanos (CIDH-OEA) foi provocada para analisar a Responsabilidade Internacional do Estado brasileiro.

\section{A RESPONSABILIDADE INTERNACIONAL NO CASO MARIA DA PENHA}

Em 1998, a impunidade e a inefetividade do sistema judicial frente à violência doméstica contra as mulheres no Brasil motivou, a apresentação do caso à Comissão Interamericana de Direitos Humanos da Organização dos Estados Americanos (CIDHOEA), por meio de petição conjunta das entidades CEJIL-Brasil que é o Centro para a Justiça e o Direito Internacional e CLADEM-Brasil, que é o Comitê Latino-Americano e do Caribe para a Defesa dos Direitos da Mulher (OEA, 2001).

Os peticionários alegaram à Corte Internacional que o governo brasileiro perdoou, durante anos a coabitação conjugal, a violência doméstica perpetrada na cidade de Fortaleza, no estado do Ceará, por Marco António Heredia Viveiros contra sua esposa 
na época, Maria da Penha, com quem ele havia três filhas, culminando em duas tentativas de assassinato em sua casa e mais agressões em maio e junho de 1983.

No campo jurídico a omissão do Estado brasileiro afrontava a Convenção Interamericana para Prevenir, Punir e Erradicar a Violência contra a Mulher - a "Convenção de Belém do Pará" - ratificada pelo Brasil em 1995. Assim, o estado brasileiro tem o dever de implementar políticas públicas voltadas a prevenção, a punição e a erradicação da violência contra a mulher, em concordância com os parâmetros internacionais e constitucionais, causando uma ruptura no ciclo perverso de violência que, banalizado e legitimado, abate muitas vidas dentro da população brasileira. Tal omissão ocasionou à condenação sofrida pelo Brasil no caso da Maria da Penha.

A partir de uma sintética sequência dos acontecimentos de responsabilização internacional do Estado brasileiro, pode se observar que o caso foi apresentado à Comissão Interamericana de Direitos Humanos somente no dia 20 de agosto de 1998, onde o órgão admitiu uma petição de crime de violência doméstica (caso 12.051), pela primeira vez. O Brasil recebeu a denúncia com os documentos juntados pela Peticionária em 19 de outubro do mesmo ano. Após três notificações para que prestasse informações e exercesse o contraditório, nos dias "19 de outubro de 1998, 04 de agosto de 1999 e 07 de agosto de 2000, o Estado brasileiro quedou-se silente, razão pela qual lhe foi aplicado o artigo 42 do Regulamento da Comissão, ou seja, ter os fatos narrados como verdadeiros" (CORREA; CARNEIRO, 2010).

Cabe destacar que, em nenhum momento do procedimento houve uma manifestação do Estado brasileiro, sendo interpretado como se não houvesse uma aceitação de qualquer solução amistosa, conforme o Regulamento da Comissão solicita. No dia 1 de novembro de 2000, com a finalização e transmissão do relatório do caso, novamente, o estado permaneceu inerte, sem se manifestar ou atender a recomendação feita pela Comissão (OEA, 2001)

Em 2001, em decisão inédita, a Comissão Interamericana condenou o Estado brasileiro por negligência e omissão em relação à violência doméstica, recomendando 
ao Estado, dentre outras medidas, de acordo com Informe 54/01, caso 12.051, Maria da Penha Fernandes versus Brasil, 16/04/01, "prosseguir e intensificar o processo de reforma, a fim de romper com a tolerância estatal e o tratamento discriminatório com respeito à violência doméstica contra as mulheres no Brasil”. Ainda, conforme o Informe 54/01, adicionou a Comissão Interamericana que

essa tolerância por parte dos órgãos do Estado não é exclusiva deste caso, mas é sistemática. Trata-se de uma tolerância de todo o sistema, que não faz senão perpetuar as raízes e fatores psicológicos, sociais e históricos que mantêm e alimentam a violência contra a mulher (OEA, 2001).

Logo após a decisão da Comissão Interamericana, em outubro de 2002, Marco Antônio Viveiros foi finalmente preso. Além disso, a mídia passou a transmitir informações sobre diversos casos de violência cometidos contra mulheres no Brasil e entrevistas com Maria da Penha, contribuindo para a conscientização do problema e estimulando as mulheres a denunciar a violência doméstica que foi cometida contra elas. Faz-se importante destacar que paulatinamente o Brasil, mesmo de forma lenta, foi estabelecendo no seu ordenamento jurídico algumas alterações legais que igualavam a mulher ao homem.

O novo código civil do Brasil, promulgado em 2002, revogou o antigo código civil e deu tratamento igual a homens e mulheres em todas as esferas. O Código Civil Brasileiro de 1916 tratava homens e mulheres de forma desigual. Por exemplo, os códigos definem o casamento de maneira diferente. $\mathrm{O}$ domicílio de uma mulher era o mesmo que o de seu marido. Um homem tinha dez dias para apresentar uma petição para anular seu casamento, se sua esposa fosse anteriormente deflorada. Ele era o "chefe" do lar e a mulher era sua companheira. Nesse sentido, o novo código civil revogou expressões como "chefe da sociedade conjugal". Essas iniciativas visavam promover o princípio da igualdade entre homens e mulheres garantido na Constituição Brasileira e nos tratados internacionais de direitos humanos (BRASIL, 2002).

Nesse contexto é salutar destacar que, diversamente de dezessete países da América Latina, o Brasil até o ano de 2006 não dispunha de legislação específica a respeito da violência contra a mulher. Mesmo a condenação do Estado brasileiro tendo ocorrido 
no ano de 2001, somente em 07 de agosto de 2006, e por meio do processo de responsabilidade internacional, o Brasil aprovou, como consequência de sua

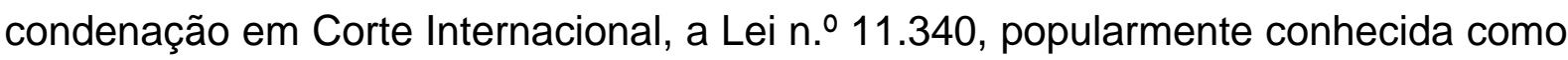
"Lei Maria da Penha".

\section{CONSIDERAÇÕES FINAIS}

A partir da interseção entre a violência doméstica cometida contra Maria da Penha Maia Fernandes e o instituto da Responsabilidade Internacional, verificou-se como a aplicação de um instituto internacional, por meio da Comissão Interamericana de Direitos Humanos da Organização dos Estados Americanos (CIDH-OEA) influenciou a criação de uma legislação que assegura os direitos das mulheres no Estado brasileiro. A condenação do Estado brasileiro gerou a responsabilidade do estado reparar o caso de violência, que se verificou com a prisão do ex-companheiro de Maria da Penha, assim como de criar legislação específica para a proteção dos direitos das mulheres, que se verificou com as mudanças registradas no Novo Código Civil e na promulgação da Lei n. 11.340/06, popularmente conhecida como "Lei Maria da Penha".

\section{REFERÊNCIAS}

ALEXANDRINO, I. D. A. S. (2017). A responsabilidade internacional dos estados perante tribunais internacionais. Revista Eletrônica da Faculdade de Direito de Franca, 12(2), 103-132.

BARSTED, L. L. (2011). Lei Maria da Penha: uma experiência bem-sucedida de advocacy feminista. CAMPOS, Carmen Hein de (Org. $\left.{ }^{a}\right)$. Lei Maria da Penha comentada em uma perspectiva jurídico-feminista. Rio de Janeiro: Lumen Juris, p. 1339.

BOTELHO, M. C.; TABISZ, D. (2017). A responsabilidade internacional do estado e a violação dos direitos humanos trabalhistas. Corpo Editorial, 5(3), 141. 
BOTELHO, T. (2005). Direitos humanos sob a ótica da responsabilidade internacional. Revista da Faculdade de Direito de Campos, Ano VI, (6).

BRASIL. (2002). Código Civil brasileiro. São Paulo: Saraiva.

BRASIL. (2006) Lei n.o 11.340/06. Disponível em: $<$ http://www.planalto.gov.br/ccivil_03/_ato2004-2006/2006/lei//11340.htm>. Acesso em: 20.jun.2020.

CORREA, A. J.; CARNEIRO, S. R. O sistema de proteção dos direitos humanos e o caso maria da penha. Revista da Católica. V. 3, N. 5, jan./jul. 2010.

ONU. International Law Commission. (2001). Draft articles on responsibility of states for internationally wrongful acts. Yearbook of the International Law Commission, 2(2), 49.

OEA. (2001). Comissão Interamericana de Direitos Humanos. Relatório $n .54 / 01$, caso 12.051 (Maria da Penha Maia Fernandes $\mathrm{x}$ Brasil). Disponível em: $<$ http://www.sbdp.org.br/arquivos/material/299_Relat\%20n.pdf>. Acesso em: 20.jun.2020.

RAMOS, A. D. C. (2005). Responsabilidade internacional do Estado por violação de direitos humanos. Revista CeJ, 9(29), 53-63.

SANTOS, C. M.; IZUMINO, W. P. (2005) Violência contra as mulheres e violência de gênero: notas sobre estudos feministas no Brasil. Estudios interdisciplinarios de América Latina y el Caribe, v. 16, n. 1.

Enviado: Novembro , 2020.

Aprovado: Novembro, 2020. 